\title{
THE ROLE OF PARTICLE SIZE DISTRIBUTION ON BIOAVAILABILITY OF CYCLOSPORINE: NOVEL DRUG DELIVERY SYSTEM
}

\author{
Tomáš Andrýsek
}

Department of Biopharmacy and Pharmacokinetics; IVAX-CR a. s.; Ostravská 29; 74770 Opava 9; Czech Republic

Received: October 18, 2001

Key words: Cyclosporine / Bioavailability / Drug delivery / Pharmacokinetics / Particle size distribution

During the long period of cyclosporine-containing dosage forms development a lot of significant findings have been done especially in the field of drug delivery systems. Currently available drugs are based, from technological point of view, on self-dispersible drug delivery systems, which contain cyclosporine solved in pharmaceutically acceptable vehicle. One can find difference among particular systems a) at particle size distribution after dispergation, b) at composition and c) at bioavailability of cyclosporine. As far as improvement of bioavailability between original brand leader formulation Sandimmune ${ }^{\circledR}$ and recent brand leader formulation $\mathrm{Neoral}^{\circledR}$ was followed by significant improvement in particle size distribution it was generally assumed that the reason for this improvement have been found. Several other formulations e.g. Consupren ${ }^{\circledR}$ or SangCyA ${ }^{\circledR}$ - self-dispersible systems, more or less correspond with above mentioned theory that smaller is better and by this principle bridged liquid based dosage forms with solid dosage forms. Bioavailability of novel drug delivery system which gives coarse dispersion with average particle size between 1-150 $\mu \mathrm{m}$ when dispersed have been tested on healthy volunteers. No difference among pharmacokinetic parameters of novel drug delivery system and microemulsion system have been observed in spite of fact that average particle size of novel system is almost $1000 \times$ bigger.

\section{INTRODUCTION}

Cyclosporine containing dosage forms were introduced for use in transplantations two decades ago, and are the basis of most immunosuppressive protocols after solid organ transplantation ${ }^{1}$. Physico-chemical properties of cyclosporine does not allowed formulate only simple preparation for oral administration, but from the pharmaceutical point of view we should speak about drug delivery systems. Character of cyclosporine initiated step by step development of final dosage forms bearing in minds demands on safe, reproducible and cheap therapeutics with adequate patient compliance.

Soft gelatine capsules and oral solutions are widely used forms for oral administration, but this characteristic does not allowed to distinguish different behaviours of particular formulations, especially in term of bioavailability.

When one looks on cyclosporine dosage forms from historical perspective some general conclusions seems to be obvious. The first registered dosage form with cyclosporine (Sandimmune ${ }^{\circledR}$, Novartis, Switzerland) was designed as an emulsion pre-concentrate, which mean that dispersed droplets were above $1 \mu \mathrm{m}$. Current brand leader formulation (Neoral $^{\circledR}$, Novartis, Switzerland) is in form of microemulsion pre-concentrat (e.g. dispersed particles were $<100 \mathrm{~nm}$ ) and was launched on the market more than 10 years after the first one. Signifi- cant improvement of treatment efficacy ${ }^{2}$ and bioavailability ${ }^{3}$ with $\mathrm{Neoral}^{\circledR}$ was reported. This improvement was connected with microemulsion character of administered drug., 5, 6,7 Thus the concept known from powder material that "smaller is better" was adopted also for liquid based dispersion systems.

Bearing in mind this situation experimental comparison between new type of formulation developed in IVAX-CR and standard microemulsion type of formulation was performed. To collate major factors the bioavailability of each system was compared to particle size distribution

\section{EXPERIMENTAL PART}

Pilot bioequivalecy study on 12 healthy volunteers (done in Phoenix Int. Life Sciences, Montreal) was aimed on comparison of bioavailability of two different formulation in form of soft gelatine capsule containing $100 \mathrm{mg}$ of cyclosporine (formulation A-GEM101 and formulation B-GEM304) - giving dispersion within the range 1-150 $\mu \mathrm{m}$, with $\mathrm{Neoral}^{\circledR} 100 \mathrm{mg}$ capsules (formulation C). Consequently, visualisation of novel drug delivery system and precise evaluation of particle size distribution were done.

Based on the visual observation the novel system was denominate as GEM (Gel based EMulsion). 


\section{METHODS}

\section{Bioequivalence study}

This open-label, randomised 3-period crossover study was designed for 12 caucasian healthy male volunteers, within $18-45$ year of age and body weight $\pm 10 \%$ of ideal one. The test medications and the reference medication were to be administered in randomised sequence as single oral doses under the fasted condition. Each dose contained $200 \mathrm{mg}$ cyclosporine (two capsules of $100 \mathrm{mg}$ ). The duration of the washout period between treatments was to be at least 7 days. In each study period, 14 blood samples were to be taken before administration at 20 , 40, $60 \mathrm{~min}$, and 1.5, 2, 2.5, 3, 4, 5, 6, 8, 12 and 24 hours after administration. Adverse events were to be monitored during the entire study.

Blood was to be taken from the antecubital vein into EDTA plastic tubes (Sarstedt Monovettes). The samples were to be deep-frozen $\left(-20^{\circ} \mathrm{C}\right)$.

Cyclosporine whole blood concentrations were determined by means of a specific RIA.

$\mathrm{AUC}_{(0-\infty)}$ and Cmax were defined as the primary variables for the evaluation of bioavailability. $\mathrm{AUC}_{(0-\mathrm{t})}$, tmax, t1/2, MRT(0-t), MRT(0- $)$, and Frel were secondary variables.

From the concentration/time data of the parent compound, the pharmacokinetic parameters were to be determined for each individual data set by means of non-compartmental analysis using TopFit 2.0.

Cmax and tmax were to be taken directly from the observed concentration-time data. The elimination rate constant (kel) was to be calculated by log-linear least squares regression analysis of the terminal part of the plasma concentration-time curve. The area under the concentration-time curve $(\mathrm{AUC} 0 \rightarrow \mathrm{t})$ was to be calculated up to the last measurable concentration-time point (t) by the linear trapezoidal rule. Extrapolation to infinity $(\mathrm{AUC} 0 \rightarrow \mathrm{t}, \mathrm{AUC} 0 \rightarrow \infty)$ was to be done by dividing the last observed concentration by the elimination rate constant.

\section{Statistical analysis}

Arithmetic means, standard deviations, and medians were to be calculated for concentration/time data.

For tmax and $\mathrm{t} 1 / 2$, arithmetic means, standard deviations, and $95 \%$-confidence intervals for means were to be calculated. For Cmax, $\operatorname{AUC}(0-t), \operatorname{AUC}(0-\infty)$, and Frel, geometric means, standard deviations, and 95\%-confidence intervals for means were to be calculated.

The primary variables $\mathrm{AUC}(0-\infty)$ and $\mathrm{Cmax}$, after logarithmic transformation, were to be subjected to an ANOVA with the factors subject, formulation and period. For the evaluation of bioequivalence, $90 \%$-confidence intervals were to be calculated. The accepted bioequivalence ranges were [0.80-1.25] for AUCs and [0.70-1.43] for Cmax, respectively.

\section{Particle size evaluation and visualization}

Mastersizer Micro, version 2.18 (Malvern Instruments Ltd), evaluated particle size distributions of novel GEM formulations. Purified water, stirred to 1400 revolution was used as medium which keeps particle flowing throughout the measuring cell. Measuring was done in ambient temperature.

To visualize particles, which can form in vivo after dispergation in GI-tract or which are forming in situ prior administration when patient "dilute" dosage form with water, photomicroscope technique was used.

Equipment: laboratory microscope (Peraval, CarlZeiss Jena), equipped with colour CCD camera COHU/ PC with picture analysis system Lucia ${ }^{\circledast}$, Laboratory Imaging.

Dispersion: $0.15 \mathrm{~g}$ of formulation was poured in to $10 \mathrm{ml}$ of purified water and vigorously shaken for 10 second.

\section{RESULTES}

\section{Vizualization}

Visualization showed that particles created in aqueous milieu have gel character. It means that contrary to standard emulsion droplets with spherical shape they present stable shape deformation of droplets, which results to non-spherical shape. Non-spherical particles are those whose at least two diameters perpendicular to each other are not equivalent.

Based on the visual observation the novel system was denominate as GEM (Gel based EMulsion). Its photomicrograph is shown in fig. 1 .

In accordance with the observation, gel emulsion (GEM) is to be understood as dispersion of particles of gel character in aqueous phase.

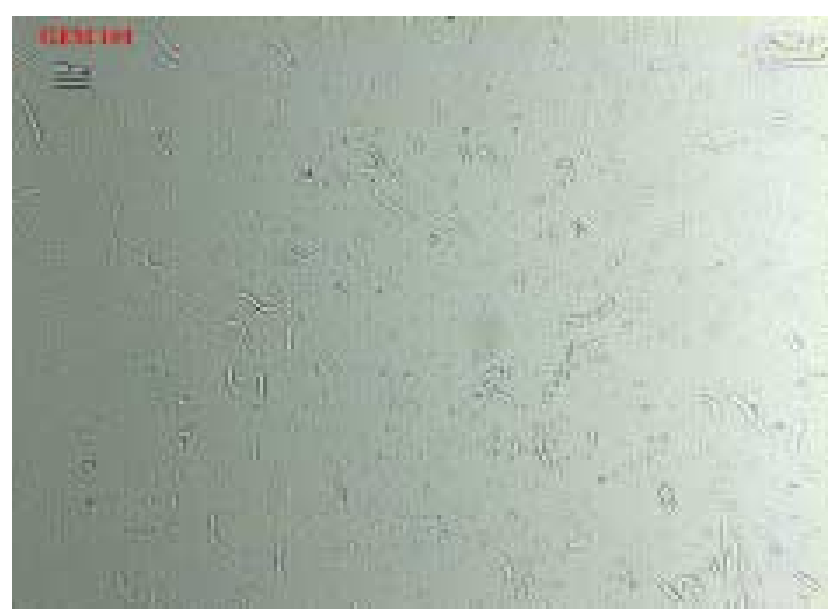

Fig. 1. Photomicrograph of gel based emulsion (GEM) 
Novel drug delivery system

\begin{tabular}{|c|c|c|c|c|c|}
\hline Parameter & $\begin{array}{r}\text { T1/2 } \\
{[\mathrm{h}]}\end{array}$ & $\begin{array}{r}\text { Tmax } \\
{[h]}\end{array}$ & $\begin{array}{r}\text { Cmax } \\
{[\mathrm{ng} / \mathrm{ml}]}\end{array}$ & $\begin{array}{r}\operatorname{AUC}(0-t) \\
{\left[\mathrm{ng}^{*} \mathbf{h} / \mathrm{ml}\right]}\end{array}$ & $\begin{array}{r}\operatorname{AUC}(0-00) \\
{\left[\mathrm{ng}^{*} \mathbf{h} / \mathrm{ml}\right]}\end{array}$ \\
\hline Formulation: & $\mathbf{A}$ & & & & \\
\hline Arit.Mean & 6.24 & 1.33 & 1372.69 & 4631.75 & 4861.85 \\
\hline S.D. & 1.3 & 0.33 & 351.28 & 1204.56 & 1241.87 \\
\hline Geom.Mean & 6.12 & 1.3 & 1329.84 & 4483.35 & 4712.35 \\
\hline Minimum & 4.06 & 1 & 908.1 & 2635.32 & 2873.57 \\
\hline Maximum & 8.24 & 2 & 1930.3 & 6432.76 & 6684.33 \\
\hline Formulation: & B & & & & \\
\hline Arit.Mean & 6.41 & 1.5 & 1196.49 & 4430.33 & 4696.56 \\
\hline S.D. & 1.3 & 0.48 & 308.26 & 1032.91 & 1143.13 \\
\hline Geom.Mean & 6.29 & 1.43 & 1161.84 & 4326.15 & 4576.94 \\
\hline Minimum & 4.21 & 1 & 851.8 & 3130.66 & 3254.08 \\
\hline Maximum & 8.93 & 2.5 & 1785 & 6206.13 & 6643.15 \\
\hline Formulation: & C / Reference & & & & \\
\hline Arit.Mean & 6.13 & 1.33 & 1358.95 & 4647.01 & 4887.55 \\
\hline S.D. & 1.32 & 0.33 & 380.35 & 1358.41 & 1430.5 \\
\hline Geom.Mean & 5.99 & 1.3 & 1307.19 & 4472.8 & 4705.55 \\
\hline Minimum & 3.92 & 1 & 820.7 & 2953.47 & 3028.58 \\
\hline Maximum & 7.87 & 2 & 1805.3 & 7330.08 & 7686.89 \\
\hline
\end{tabular}

Fig. 2. Summary of pharmacokinetic data

Pharmacokinetis and bioequivalency data

Summary table of pharmacokinetic data is shown in the fig. 2.

The ANOVAs indicated a statistically significant medication effect for all three variables and a significant period effect for $\mathrm{AUC}_{(0-\infty)}$ and $\mathrm{AUC}_{(0-\mathrm{t})}(\mathrm{p}<0.05)$. For the AUC- and Cmax-ratios, the fig. 3 shows confidence intervals $(\mathrm{CI})$ and point estimates.

\section{Particle size evaluation}

Figure 4 shows histograms of particle size distribution of formulation A (GEM101) and formulation B (304). Effective diameter of formulation A (resp. B) deduced from histogram was $92.05 \mu \mathrm{m}(36.23 \mu \mathrm{m})$.

\section{DISCUSSION}

This study was performed in a population of young healthy males (19-39 years) according to the Clinical Study Protocol. The study medications appeared to be safe and well tolerated.

This clinical study showed that formulation A and B meet criteria for bioequivalency with reference formulation $\mathrm{C}$.

Comparison of effective size of particles created after dispergation on the other hand showed that formulations A and B give approx. 1000 times larger particles then reference formulation $\mathrm{C}$.

These findings interfere with previous concept that smaller is better.

\begin{tabular}{llrrr}
\hline & & $\begin{array}{r}\text { lower 90\%- } \\
\text { confidence limit }\end{array}$ & $\begin{array}{r}\text { point } \\
\text { estimate }\end{array}$ & $\begin{array}{r}\text { upper 90\%- } \\
\text { confidence limit }\end{array}$ \\
\hline AUC $(0-\infty)$ & Form A / Reference & 0.93 & 1.00 & 1.08 \\
& Form B / Reference & 0.88 & 0.97 & 1.07 \\
\hline AUC $(0-t)$ & Form A / Reference & 0.93 & 1.00 & 1.09 \\
& Form B / Reference & 0.87 & 0.97 & 1.07 \\
\hline Cmax & Form A / Reference & 0.90 & 1.02 & 1.16 \\
& Form B / Reference & 0.79 & 0.89 & 1.01
\end{tabular}

Fig. 3. Bioequivalence criteria 
a) formulation A - GEM101

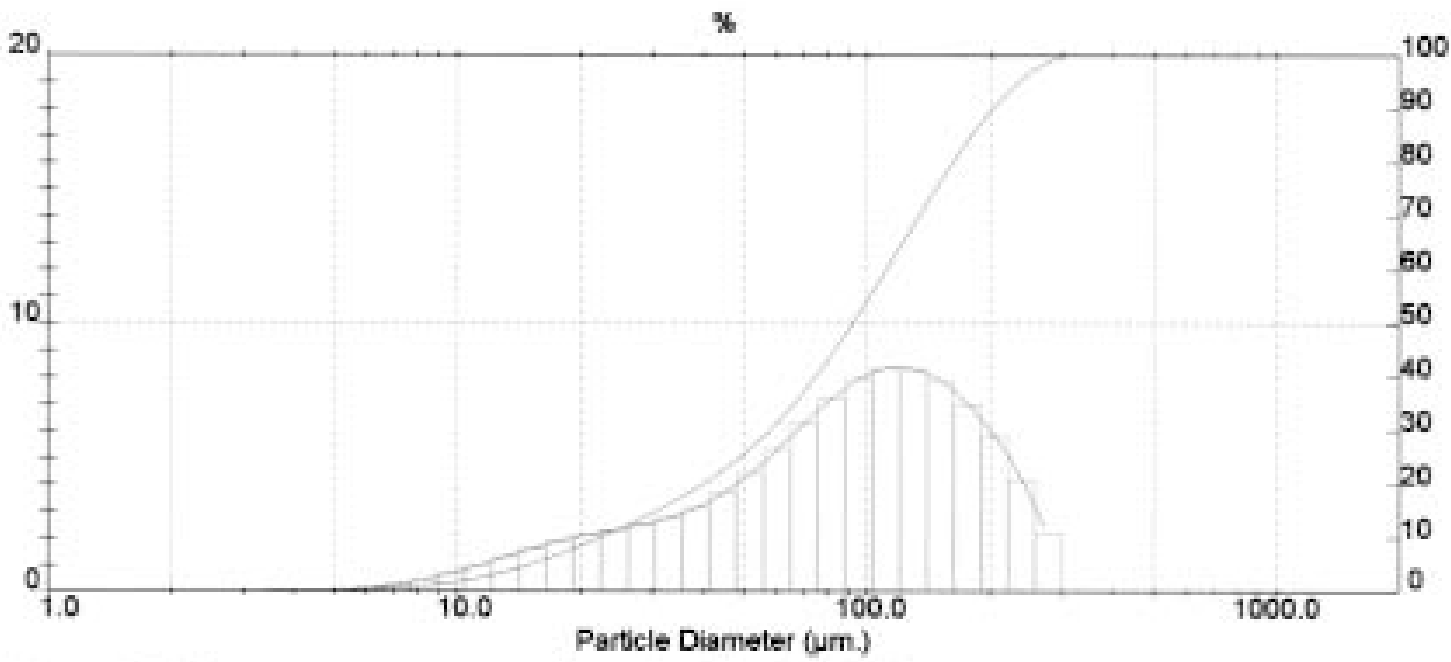

Malvern instruments Lid

Malvern, UK

Mastersizer Micro Ver. 2.18

Tei: $=+[44](0) 1684-892456 \mathrm{Fax}+[44](0) 1684-892789$

b) formulation B - GEM 304

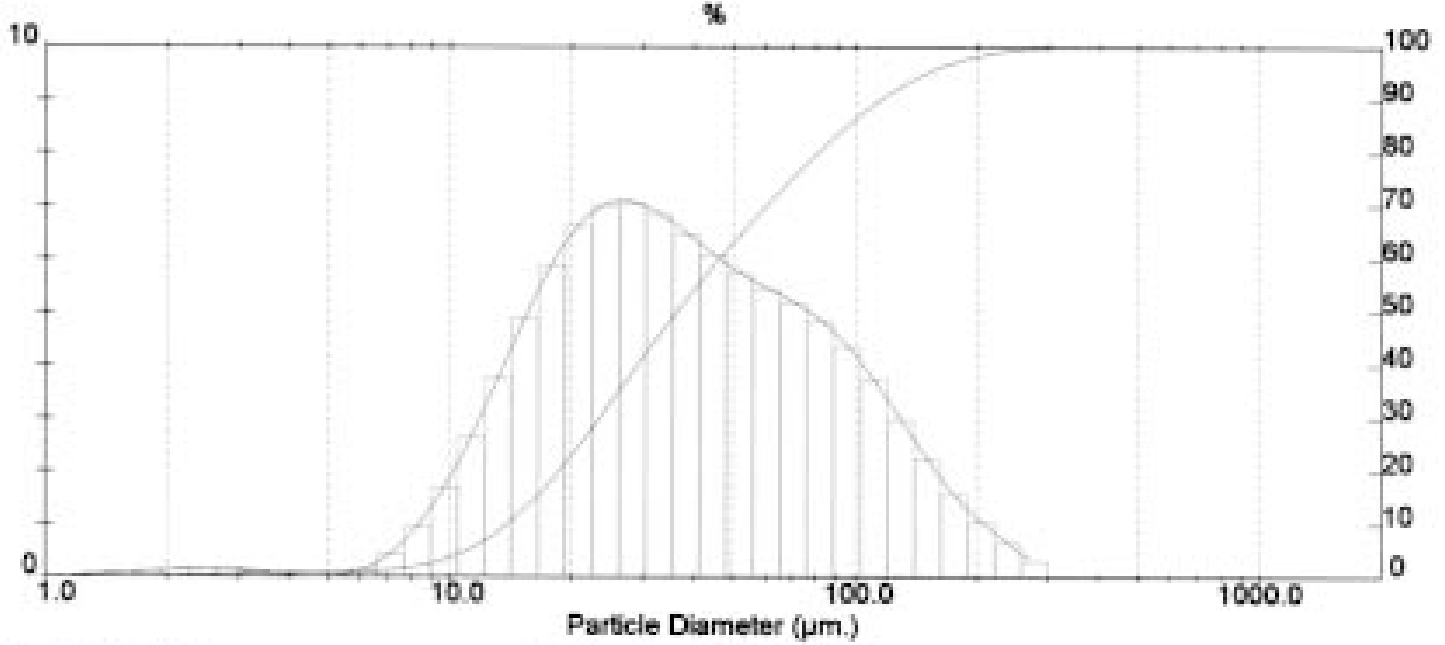

Malvern Instruments Ltd

Malvern, UK

Mastersizer Micro Ver. 2.18

Serial Number: 34044-02

Tel: $=+[44](0) 1684-892456 \mathrm{Fax}+[44](0) 1684-892789$

Fig. 4. Histogram of particle size distribution

\begin{tabular}{|c|c|c|c|c|}
\hline & Sandimmun $^{\circledR}$ & Neoral $^{\circledR}$ & Consupren $^{\circledR}$ & SangCyA $^{\circledR}$ \\
\hline Eff. diameter & $3.73 \mu \mathrm{m}^{\text {a) }}$ & $0.03 \mu \mathrm{m}^{\text {b) }}$ & $1.73 \mu \mathrm{m}^{\text {a) }}$ & $0.05 \mu \mathrm{m}^{\text {b) }}$ \\
\hline CV\% & 61.3 & 12.9 & 22.3 & 15.1 \\
\hline
\end{tabular}

Fig. 5. Effective diameter of dispersed particles (current cyclosporin containing drugs).

Eff. Diameter - effective diameter

CV\% - coeficient of variation (\%)

a) optical microscope technique; computer analysis by Lucia ${ }^{\circledR}$, Laboratory Imaging Inc.

b) dynamic laser scattering performed on BI 200SM, BI9000 AT digital correlator (Brookhaven Inc.) with argon $514 \mathrm{~nm}$ laser (Lexel Laser Inc.) 
Nevertheless, improvements in bioavailability which consequent on better dispergation abilities besides to $\mathrm{Neoral}^{\circledR}$ (e.g. giving smaller particles after administration) was described with Consupren ${ }^{\circledR}$ (emulsion giving formulation; Galena, Czech Republic) ${ }^{8}$ and SangCya ${ }^{\circledR}$ (microdispersion giving formulation; SangStat, USA) ${ }^{9}, 10$. Summary of average particle size of mentioned cyclosporin containing formulations is given in the figure 5 (adopted) ${ }^{11}$.

Meantime, biofarmaceutical experiments focused on correlation between particle size distribution and bioavailability on dogs were conducted. Those experiments showed that the same improved bioavailability is achievable with systems giving particle size distribution in near submicron range ${ }^{12}$. Consequently, no correlation between particle size distribution resp. molecular weight of aggregation and bioavailability was observed when model microdispersed systems with $141 \mathrm{~nm}(309 \mathrm{~nm}$ and $1001 \mathrm{~nm}$ ) average size of particles were evaluated ${ }^{13}$.

Based on current findings it is possible to deduce that particle size distribution is not the crucial point for bioavailability of hydrophobic drugs like cyclosporine from solution based systems. The reasons for good bioavailability of cyclosporine from GEM system are as follows:

1. physical - in spite the fact that GEM dispersion is rather coarse it has different properties comparing to emulsion; the physical reason for that could be seen in ability to overcome unstirred water layer in the lumen of a small intestine and adhere into the intestinal wall - thus could be ensure sufficient time and concentration gradient for absorption of cyclosporine

2. metabolism - all mentioned drugs and formulation with cyclosporine contain nonionic surfactant which probably can affect permeation or absorption of cyclosporine through the intestinal wall.

The effects of excipients on drug bioavailability have been documented since the early 1990s. It was described that surfactants can cause reversible microvillae local damage and that way increase permeability through the intestinal wall ${ }^{14}$. Disruption of the cellular tight junction is another potential effect of excipients observed on Caco-2 cells model ${ }^{15}$. More likely than effect on tight junction the affection of excipients modified activity of multi drug resistence protein - efflux transporter, MDR 1, also called P-glycoprotein (P-gp.) or metabolic enzymes (cytochrom P450 subclass 3A4; CYP3A4) ${ }^{16}$. Not only surfactants but also polyethylene glycol 300 was reported as MDR 1 inhibitor with effect on membrane fluidity.

CYP3A4 activity is also modified by excipients. Different level of suppression of its activity was reported in coherence with application of Cremophor RH 40, lecithin - taurocholat admixture, Tween 20 and Vitamin E TPGS $^{17}$.

\section{CONCLUSION}

Novel gel based emulsion giving drug delivery system for cyclosporine (GEM or GEMDDS) was developed and tested. In spite the fact that dispergation is not as good as in microemulsion pre-concentrates and effective diameter of created particles meets almost $100 \mu \mathrm{m}$ size, bioequivalency with microemulsion preparation was proved. The role of particle size distribution of nascent dispersion and its influence on bioavailability was minimized in this novel drug delivery system.

\section{LITERATURE}

1. Kahan, B. D. (1989) Cyclosporine. New. Engl. J. Med.; 321; 1725-1738.

2. Pollard, S. G., Lear, P. A., Ready, A. R., Moore, R. H., Johnson, R. W. (1999) Comparison of microemulsion and conventional formulation of cyclosporine $\mathrm{A}$ in preventing acute rejection in de novo kidney transplant patients. The U. K. Neoral Renal Study Group. Transplantation.; Vol. 68, 9, 1325-1331.

3. Roessler, E., Herrera, S., Espinoza, O., Undurraga, A., Munoz, R., Arcos, O. and Galaz, G. (1998) Conversion from Sandimmune to Neoral in renal transplant: functional histopathological, and pharmacokinetic changes. Transplant. Proc., 30; 1756-1757.

4. Hutchinson, K. G., MacGregor, K., Embleton, J. K., Seager, H., Solomon, L. J. and Pouton, C. W. (1995) Optimizing the gastrointestinal absorbtionof hydrophobic drugs using micro-emulsions and other liquid formulations; in Formulation of poorly available drugs for oral administration (Couvreur P., Duchene D., Kalles I., ed.), Editions de Santé, Paris; 121-125.

5. Vonderscher, J., Meinzer, A. (1994) Rational for the development of Sandimmune Neoral. Transplant. proc.; 26; 2925-2927

6. Kovarik, J. M., Mueller, E. A., Niese, D. (1996) Clinical development of a cyclosporine microemulsion in transplantation. Ther Drug Monit.; 18; 429-434.

7. Noble, S., Markham, A. (1995) Cyclosporine: A review of the pharmacokinetic properties, clinical efficacy and tolerability of a microemulsion-based formulation $\left(\mathrm{Neoral}^{\circledR}{ }^{\circledR}\right.$. Drugs; 50; 924-941.

8. Duchin, K. (1997) Comparative pharmacokinetics of Consupren, Sandimmun and Neoral in healthy subjects. in Current Immunosuppression: An Update (Hakim N. S., ed.), Round Table Series 49, Royal Society of Medicine Press Ltd., London; 49; 34-35.

9. Canafax, D. M., Irish, W. D., Moran, H. B., Squiers, E., Levy, R., Pouletty, P., First, M. R., Christians, U. (1999) An individual bioequivalence approache to compare the intrasubject variability of two ciclosporin formulations, SangCya and Neoral. Pharmacology; 59; 78-88.

10. Andrýsek, T. (2000) Development of cyclosporine containing dosage forms. Thesis, Pharmaceutical Faculty, Commenius University, Bratislava (Czech language).

11. Andrýsek, T., Vrána, A., Stuchlík, M. (1998) The effect of particle size on bioavailability for cyclosporine preparations based on the formation of submicron dispersion. Eur. J. Pharm. Sci.; 8; Suppl. $1, \mathrm{~S} 77$.

12. Andrýsek, T., Pisárčik, M. (1999) Bioavailability versus physical properties in cyclosporin-containing drug delivery systems. In Proceedings from Symposium on "Lipid and surfactant dispersed system”. Moscow 26.-28. 9. 1999; 187-188.

13. Swenson, E. S, Milisen, W. B., Curatolo, W. (1994) Intestinal permeability enhancement: Efficacy, acute local toxicity and reversibility. Pharm. Res.; Vol 11; 8; 1132-1142.

14. Nerurkar, M. M., Burton, P. S., Borchardt, R. T. (1996) The use of surfactants to enhance the permeability of peptids through Caco-2 cells by inhibitin of an apically polarized efflux systém. Pharm. Res.; 13; 528-534. 
15. Hugger, E. D., Novak, B. L., Borchardt, R. T. (1999) in Bulletin Technique Gattefossé; no 92; 59-64.
16. Mountfield, R. J., Senepin, S., Isel, H., Bittner, B. (2000) An investigation into effect of common preclinical formulations on the activity of intestinal cytochrome P450 - a drug-drug interaction issue?: in Proceedings from "Millenial World Congress of Pharmaceutical Science"; 3-9030; 155. 